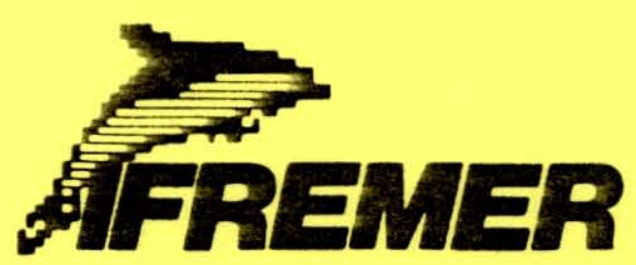

Station de la Tremblade

(J)

ECOSYSTEM MODELLING : SENSITIVITY OF PHYSICAL CHARACTERISTICS TO SPATIAL BOX DESIGN.

Cédric BACHER 


\section{ECOSYSTEM MODELLING: SENSITIVITY OF PHYSICAL CHARACTERISTICS TO SPATIAL BOX DESIGN.}

\section{INTRODUCTION}

The residence time of the water in different parts of the Marennes-Oléron Bay is one important characteristic of the biological system (Raillard, 1990). For instance, the primary production potentiality of a given area depends on the local turbidity and the residence time of the waters in that area. Further, global assessments of the nitrogen flow between the biological compartments and inflows from the ocean or the Charente river derived from the ecosystem model by Raillard (1990), showed the predominance of the latter term onto the former.

A new hydrological model of the Marennes-Oléron Bay yielded two dimensional velocity fields for some standard tidal levels: neap-tide, spring-tide, mean tide (Lazur, unpub.). These computations were the basis for the calculation of the transport of conservative substances throughout the Bay and were coupled to the resolution of resuspension and sedimentation equations. For this work, the instantaneous values of the bidimensional flows and the volume of each $1000 \mathrm{~m} \times 1000 \mathrm{~m}$ cell were used to estimate the residence time of water inside the Bay. Eulerian residual values were computed for the sake of simplicity. Emphasis was given to the comparison of the linear resolution of transport under steady conditions of tidal level between the box model used by Raillard and the previous model. This simplification of the equations allowed to formulate the transport process in a probabilistic fashion.

\section{MATRICIAL COMPUTATION OF THE RESIDENCE TIME.}

The figure 1 shows the numerical grid used for the hydrological model of the Bay and the area within which the residence time had to be estimated. When averaging the flows between cells in order to estimate the eulerian residual flows, each cell could be connected to the four adjacent ones (fig. 2). A connection matrix was therefore calculated to represent the flows between all the cells. Browsing the spatial grid yielded to select and to enumerate the cells that were concerned with internal exchanges of water inside the previously defined area. The next step consisted in calculating the transition matrix of exchanges between the selected cells, excluding the continental cells with which no exchange existed. By the same way a vector of exchanges between the internal cells and the boundary cells was built. For two cells number $k, 1$ corresponding for instance to the coordinates $i, j$ and $i+1, j$, the transition term between $k$ and $l$ was written:

$$
\begin{aligned}
& \mathrm{P}_{\mathrm{kl}}=\mathrm{Qx}(\mathrm{i}, \mathrm{j}) / \mathrm{V}_{\mathrm{i}}, \text { if } \mathrm{Qx}(\mathrm{i}, \mathrm{j})>0 \\
& \mathrm{P}_{\mathrm{kl}}=0 \text { otherwise, }
\end{aligned}
$$

where $\mathrm{Qx}($ ) was the mean flows table along the $\mathrm{x}$ axis derived from the transport model.

Therefore, $\mathrm{P}_{\mathrm{kl}}$ represented a probability for the water body of the cell $\mathrm{k}$ to outflow from $\mathrm{k}$ towards 1 during one time unit.

Similarly, if the coordinates of the cell 1 were $\mathrm{i}, \mathrm{j}+1$, the transition probability was written:

$$
P_{k l}=Q y(i, j) / V_{i} \text {, if } Q y(i, j)>0
$$




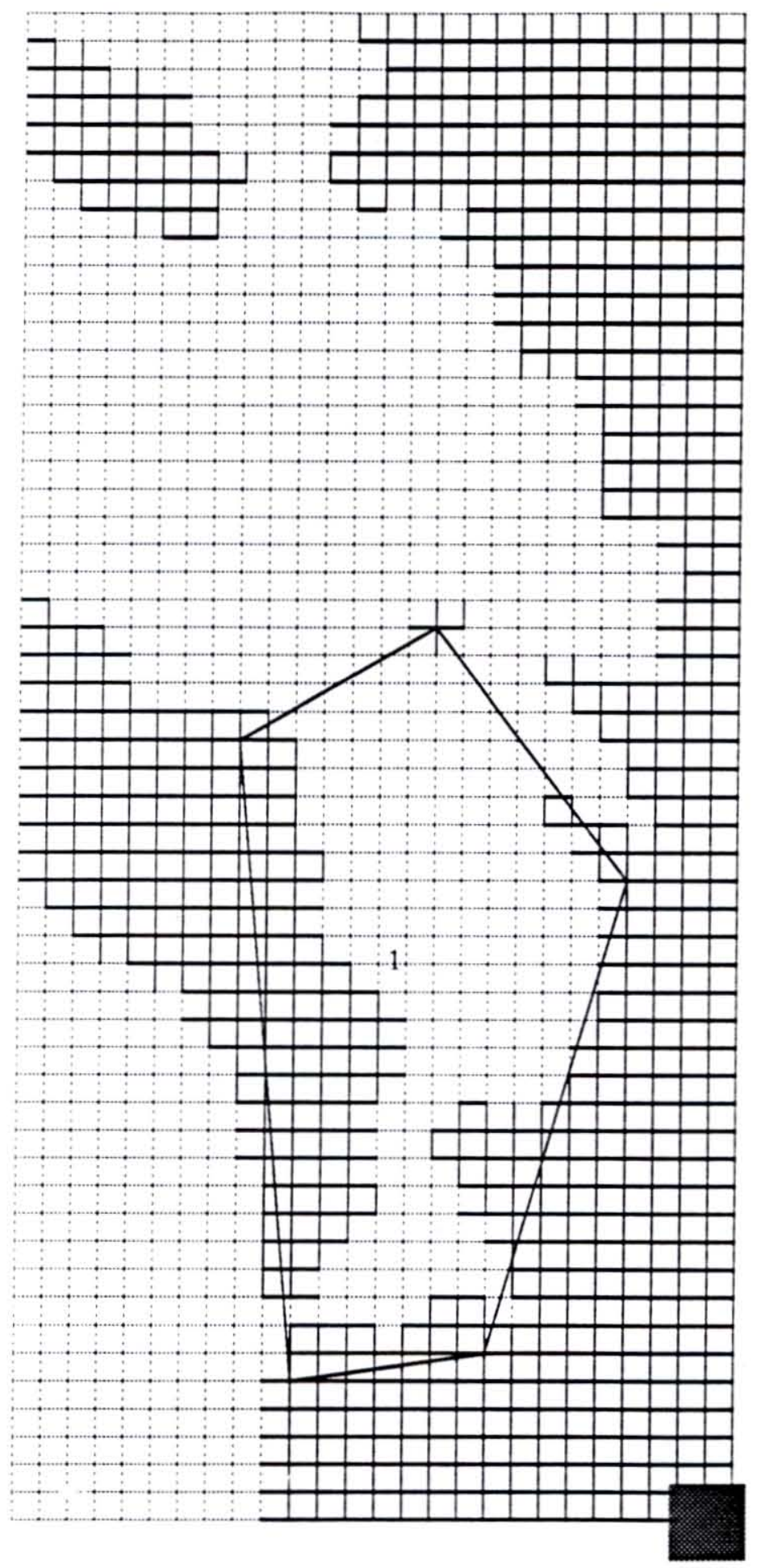

Figure 1. Schematization of the bay for the hydrodynamical model applied by Lazur (unpubl.) and used in this study for the computation of the residence time. Each cell has a $1000 \mathrm{~m}^{2}$ surface. The dotted lines represent the under water area, while solid lines represent the Oléron island, the continent and a part of the Ré island. In this study, we will focus on the residence time inside the contoured zone corresponding to the geographic boundary of the ecosystem model by Raillard (1991). 


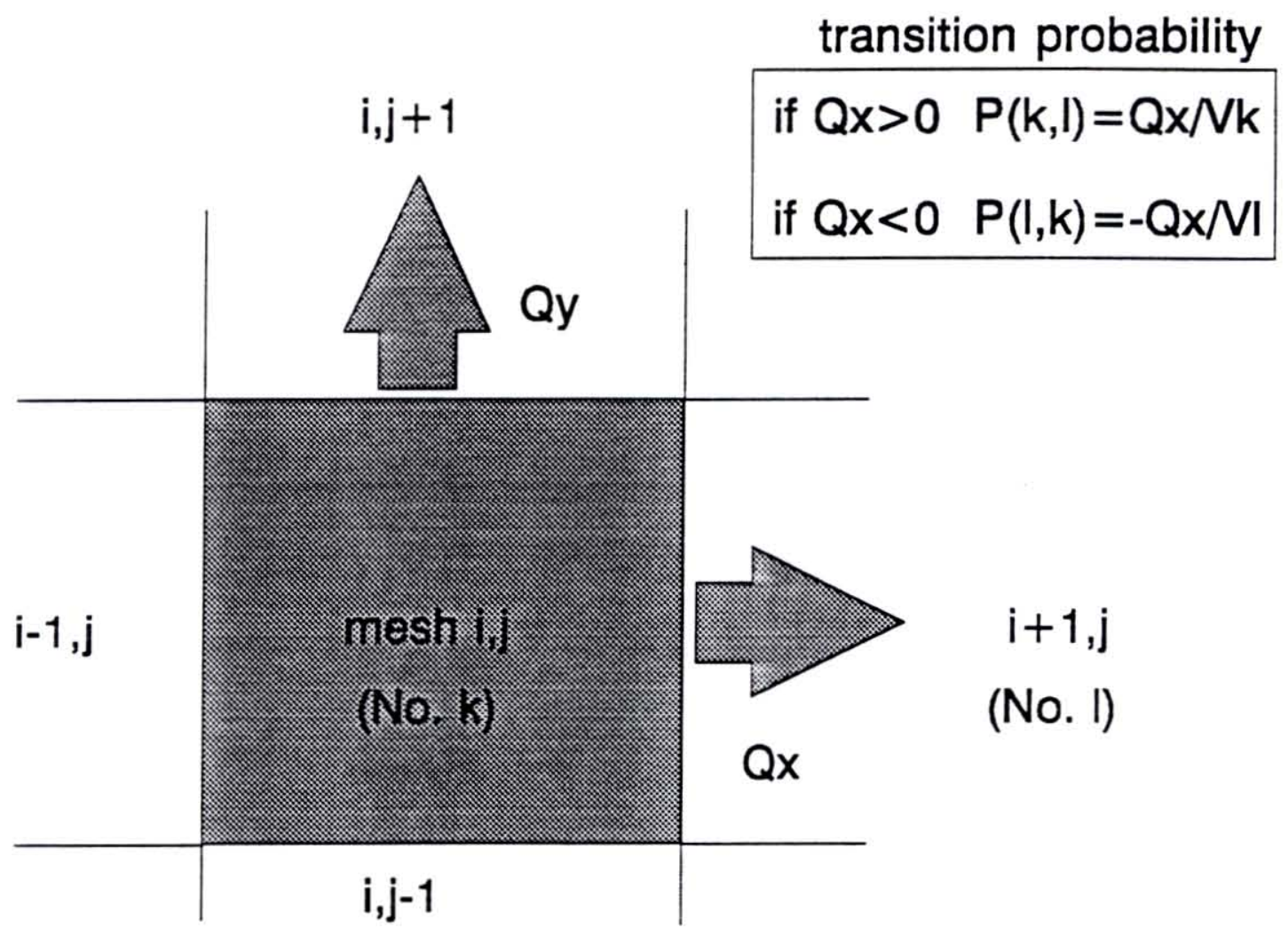

Figure 2. Representation of the residual flow between adjacent cells used by Lazur (unpub.) for the hydrodynamic model. Each cell is identified by its two coordinates $\mathrm{i}, \mathrm{j}$ and connected to the adjacent cells. The cells concerned are numbered to build the transition matrix used for the computation of the residence time. The terms of this matrix are derived from the flows and the volumes of the cells and express the probability for a water mass to flow from one cell to another durint one time unit (here the tidal period). 


$$
\mathrm{P}_{\mathrm{kl}}=0 \text { otherwise, }
$$

where $\mathrm{Qy}($ ) was the mean flows table along the y axis.

$P_{k k}$ represented the probability of remaining inside the cell $k$. The summation of the $P_{k l}$ terms was generally equal to 1 , except for the cells at the boundaries of the defined area, because of possible exchange with the external cells. These values were grouped in a vector $\mathrm{U}$ :

$$
\mathrm{U}=\left(\mathrm{P}_{10}, \ldots, \mathrm{P}_{\mathrm{n} 0}\right) \text {, }
$$

where $P_{k 0}$ represented the outflow from the cell $k$ towards the boundaries.

If $U_{h}=\left(u_{k}{ }^{h}\right)$ describes the distribution of the water masses in the cells $k$ at time $h$, the probability to flow outside the area at time $\mathrm{h}$ was written:

$$
\mathrm{p}(\mathrm{t}=\mathrm{h})=\Sigma \mathrm{P}_{\mathrm{k} 0} \cdot \mathrm{u}_{\mathrm{k}}{ }^{\mathrm{h}}
$$

The vector $\mathrm{U}_{h}$ was the iterative product of the $\mathrm{P}$ matrix during $\mathrm{h}$ time steps:

$$
\mathrm{U}_{\mathrm{h}}=\mathrm{P}^{\mathrm{h}} . \mathrm{U}_{0} \text {, }
$$

where $\mathrm{U}_{0}$ was the initial distribution of the water bodies.

Then, the residence time was equal to the average residence time, with the density function $\mathrm{p}(\mathrm{t}=\mathrm{h})$. Therefore:

$$
\mathrm{T}=\Sigma \mathrm{p}(\mathrm{h}) . \mathrm{h}
$$

(1) and (2) yielded:

$$
\mathrm{T}=\mathrm{U} \cdot\left(\Sigma \mathrm{P}^{\mathrm{h}} \cdot \mathrm{h}\right) \cdot \mathrm{U}_{0},
$$

or

$$
\mathrm{T}=\mathrm{U} \cdot \mathrm{Q} \cdot \mathrm{U}_{0}
$$

with

$$
\mathrm{Q}=\Sigma \mathrm{P}^{\mathrm{h}} \cdot \mathrm{h},
$$

or

$$
\mathrm{Q}=\mathrm{P} .\left(\mathrm{I}+\ldots+\mathrm{P}^{\mathrm{h}-1} \cdot \mathrm{h}+\ldots\right),
$$

where $\mathrm{I}$ is the identity matrix.

The expression within parentheses was the derivative of the function of $P$ :

$$
f(P)=\Sigma P^{h},
$$

which was also written :

$$
f(P)=(I-P)^{-1} \text {. }
$$

Obviously, $f(P)=(I-P)^{-2}$, so

$$
\mathrm{Q}=\mathrm{P} .(\mathrm{I}-\mathrm{P})^{-2}
$$

The initial distribution $U_{0}$ was detined in two different ways. The first purpose was to compute the residence time all over the bay. Consequently, $\mathrm{U}_{0}$ was written as the initial distribution of the water in the area :

$$
\mathrm{U}_{0}=\left(\mathrm{U}_{\mathrm{ok}}\right), \mathrm{k}=1 \ldots, \mathrm{n}
$$

with $\mathrm{U}_{0 \mathrm{k}}=\mathrm{V}_{\mathrm{k}} / \Sigma \mathrm{V}^{\mathrm{k}}$

where $\mathrm{V}_{\mathrm{k}}$ was the mean water volume derived from the hydrodynamic model.

Secondly, it was also interesting to know the residence time of one given cell $\mathrm{k} 0$ inside the area. Therefore:

$$
\mathrm{U}_{\mathrm{ok}}=0 \text { of } \mathrm{k} \# \mathrm{k} 0 \text {, and }
$$




$$
\mathrm{U}_{0 \mathrm{k} 0}=1
$$

Accordingly, it may be seen from (3) that the residence time of the cells was simply given by the terms of the vector : U . Q. Areas of high or low residence time were then mapped to give an other representation of the circulation of the water in the Bay.

\section{BOX MODEL}

The basic equation of the box model was based on the conservation of mass of each state variable:

$$
\mathrm{V}_{\mathrm{i}} \cdot \mathrm{dC}_{\mathrm{i}} / \mathrm{dt}=\Sigma \mathrm{A}_{\mathrm{ij}} \cdot \mathrm{C}_{\mathrm{i}}+\Sigma \mathrm{A}_{\mathrm{ji}} \cdot \mathrm{C}_{\mathrm{j}}+\text { sinks + sources, }
$$

where $\mathrm{C}_{\mathrm{i}}$ denotes the concentration in box $\mathrm{i}, \mathrm{A}_{\mathrm{ij}}$ the transport between $\mathrm{i}$ and $\mathrm{j}$, sinks and sources the biological process responsible for the exchanges between the biological compartments, $\mathrm{V}_{\mathrm{i}}$ the volume of the box. Both transport and volume were computed from the hydrodynamic model by taking the mean over space and time of the horizontal instantaneous velocities and the volumes of the cells.

Considering only the transport process, the computation of the transport terms and volumes yielded a transition matrix, the components of which represented the transition probabilities between the boxes. The calculation of the residence time was solved as before for one box design already used by Raillard (1991) (fig. 3). The goal of his model was to simulate the growth of oyster population in subtidal areas in the southern part of the bay during two years. Biological and hydrodynamical processes were coupled with a 15 boxes model. The results concerning residence time were compared to the ones obtained from the more precise calculation with the initial grid. For that purpose, the residence times of the cells were averaged within each box. The mean was plotted versus the value derived from the transition matrix applied to the box design.

\section{RESULTS}

1) global area.

The residence time computed for the whole area defined previously was equal to 10.3 days. It was however highly depending on the location of the cells and ranged between 0 for cells closed to the boundaries, to more than 30 days. The map of the cell residence times(fig. 4) showed that important gradients existed in the southern part of Oleron island. Cells closed to this coast commonly had a residence time around 30 days with a steep gradient towards the south-western boundary. This fact was connected with vorticities noticed in the velocity fields in that area. Other vorticities were responsible for the local gradients near the northern boundary between the Ré island and the continent. At that place, the water partly outflowed towards the north which resulted in a small residence time of 1 or 2 days. The other part was evacuated towards the south and passed through the central part of the bay with a residence time around 15 days. By the same way, the gradient showed at the boundary lying in the northern part of the Oléron island, was due to a vorticity separating the water bodies in two parts : one coming back toward the boundary and being exited with a short residence time, the second one travelling southward with longer residence time around 10 days. The central area of the Bay was homogeneous. This was explained again by the well known hydrodynamic studies which already showed high tidal excursions and residual flows. Therefore, the residence time of the waters 


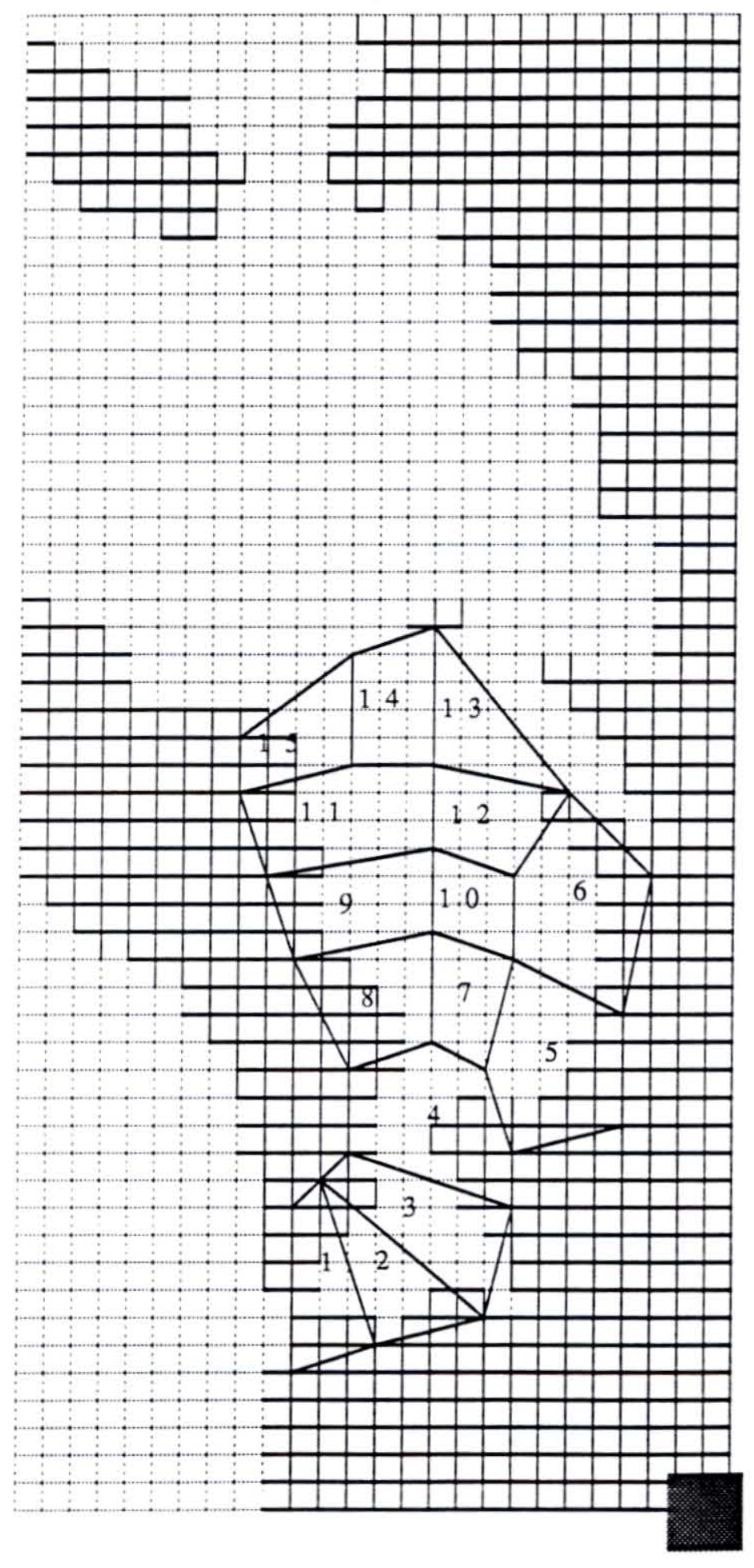

Figure 3. Box design used in the ecosystem model by Raillard (1991). The area is represented by a set of spatial boxes between which the exchange flows are computed. These flows are derived from the residual flows computed with the hydrodynamical model and integrated along the boundaries of each box. 
outside the Maumusson Pertuis was the main reason for the absence of gradient in the center. When exited, the most important part of the water went westward, and a smaller part southward. It might be expected then that the water coming out of the bay would recirculate and come again to the northern part of the Oléron island. Because of the probable high dilution of the water, the actual time residence should not be too different from another computation taking into account the recirculation of the water.

2) box model area

The mean residence time of the southern part of the bay, concerned with the oyster population cultivation, was equal to 3.5 days. It was very short compared with the mean residence time of the whole bay, because of the rapid circulation of the water generally observed. Instantaneous velocities commonly reach $1 \mathrm{~m} / \mathrm{s}$ in the narrowest area (fig. 5)

The southern trend of the water flow was seen from the spatial range of the residence time, the maximum being 10 days on the western coast, with a clear gradient from the north to the south. The values at the north-eastern boudary of the area taken into account in the box design, showed that a part of the water entering at that point outflowed again because of a gyre that was already noticed previously. The water recirculation should therefore be non negligible and could modify the local and mean residence time. This problem was already araised in other debates about the model justification, since boundary condition should be independent from the inner evolution of the variables.

Considering that the previous residual first order numerical scheme of transport was more precise than the box model, the residence time estimation derived from the box design was plotted against the local values averaged on each box (fig. 6). The former calculation showed residence time lying between a few hours (boxes 1,2) to 6 days for the box 14 and 15 closed to the north-eastern boundary. Residence time of the boxes corresponding to the main channel regularly grew from south to north (boxes 1,2 , $3,4,7,10,12,13)$. The two boxes of the eastern mid-tidal area ( 5 and 6$)$ had intermediate values of 2 and 4 days (resp.). For that computations the western sector was symetric to the previous one with residence time of 2,3 and 4.5 days (boxes $8,9,11$ ).

When compared to the mean cell values, true differences between geographic sectors seemed to be smoothed by the box calculation. Though the global range of the values was nearly the same (between almost 0 to 7 days), and the short residence time boxes ( 1 to 4 ) alike, most of the estimations differed. In the cell computation for instance, the boxes 9 and 11 had the longest residence time. This was probably due to the neighbourhood of inflow/outflow cells at the north-western boundary, which were averaged in the box computation.

Therefore, over-estimation or under-estimation of the residence time would be likewise in any complex bidimensional circulation with gyres due, for instance, to bathymetry variation and mid-tidal areas. Since the boxes 5, 6, 9 and 11 were much concerned with oyster cultivation, an inadequate representation of the physical characteristics such as residence time or spatial exchange, could result in over- or under-estimation of biological production. The box design was based on the bathymetry and hydrological information. To be fully consistent, it should also respect physical parameters such as residence time. Moreover, the numerical scheme, based on linearization and spatial and temporal integration of the horizontal flows, should be corrected. Advective transport simulation, with the same 


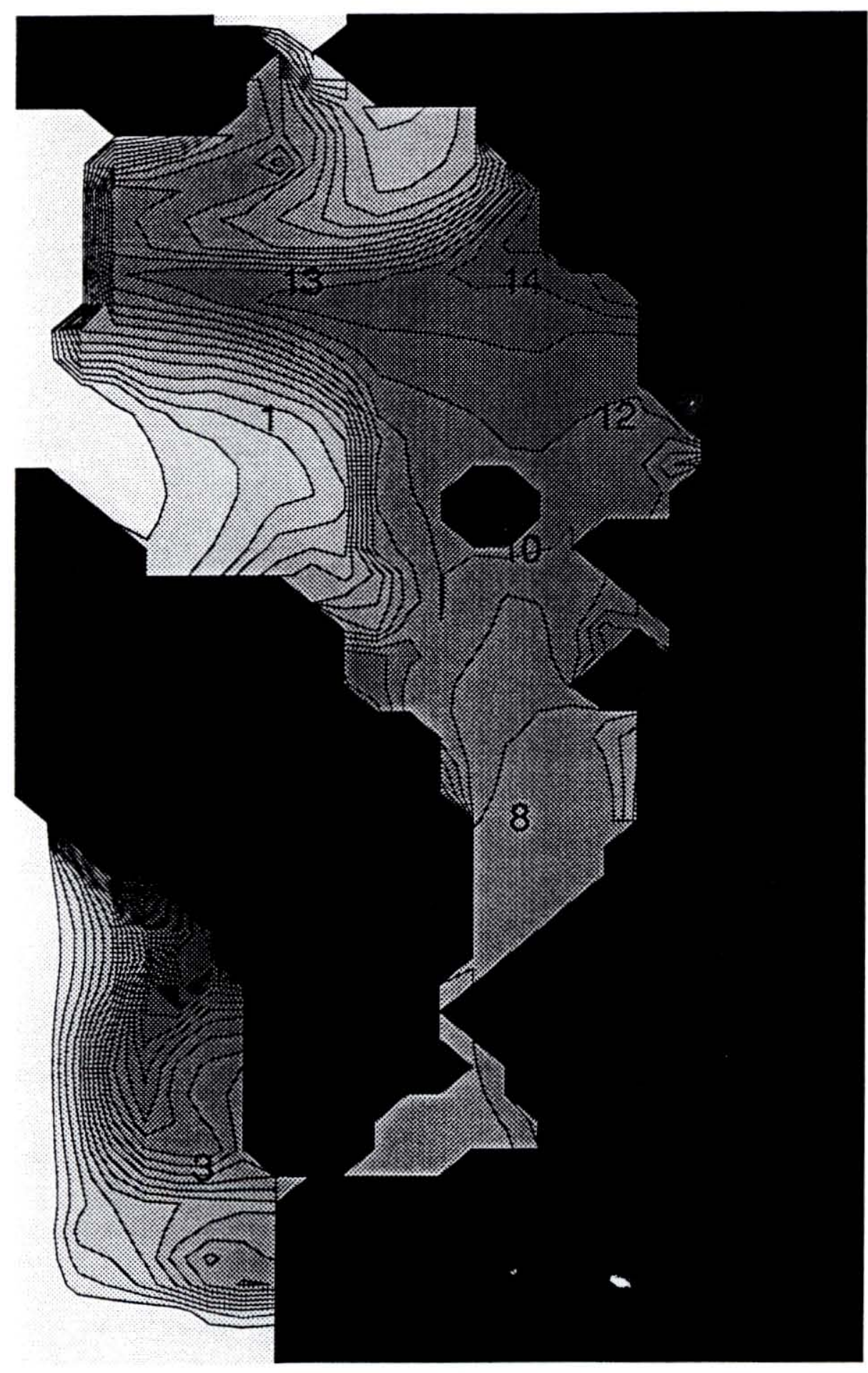

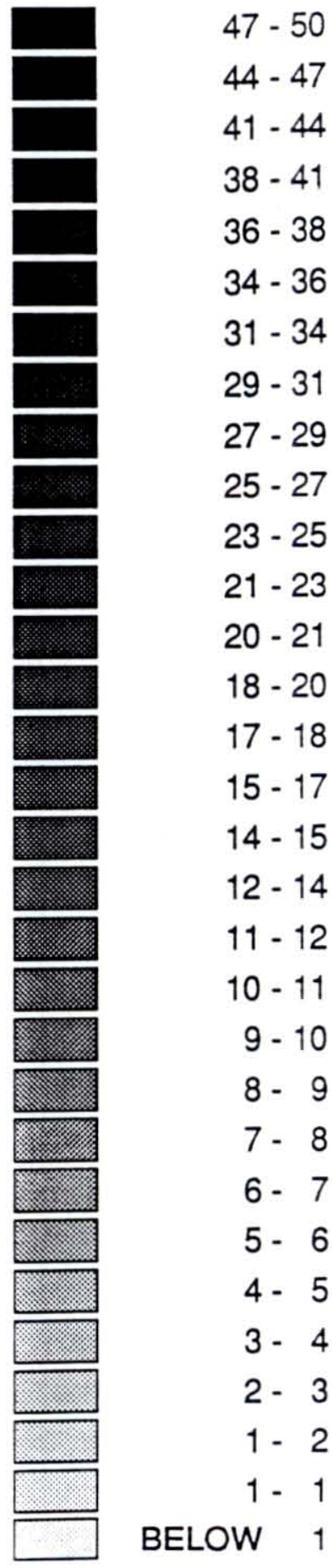

Figure 4. Mapping of the residence time computed for each cell. Figures indicate the range of the residence time in days. 


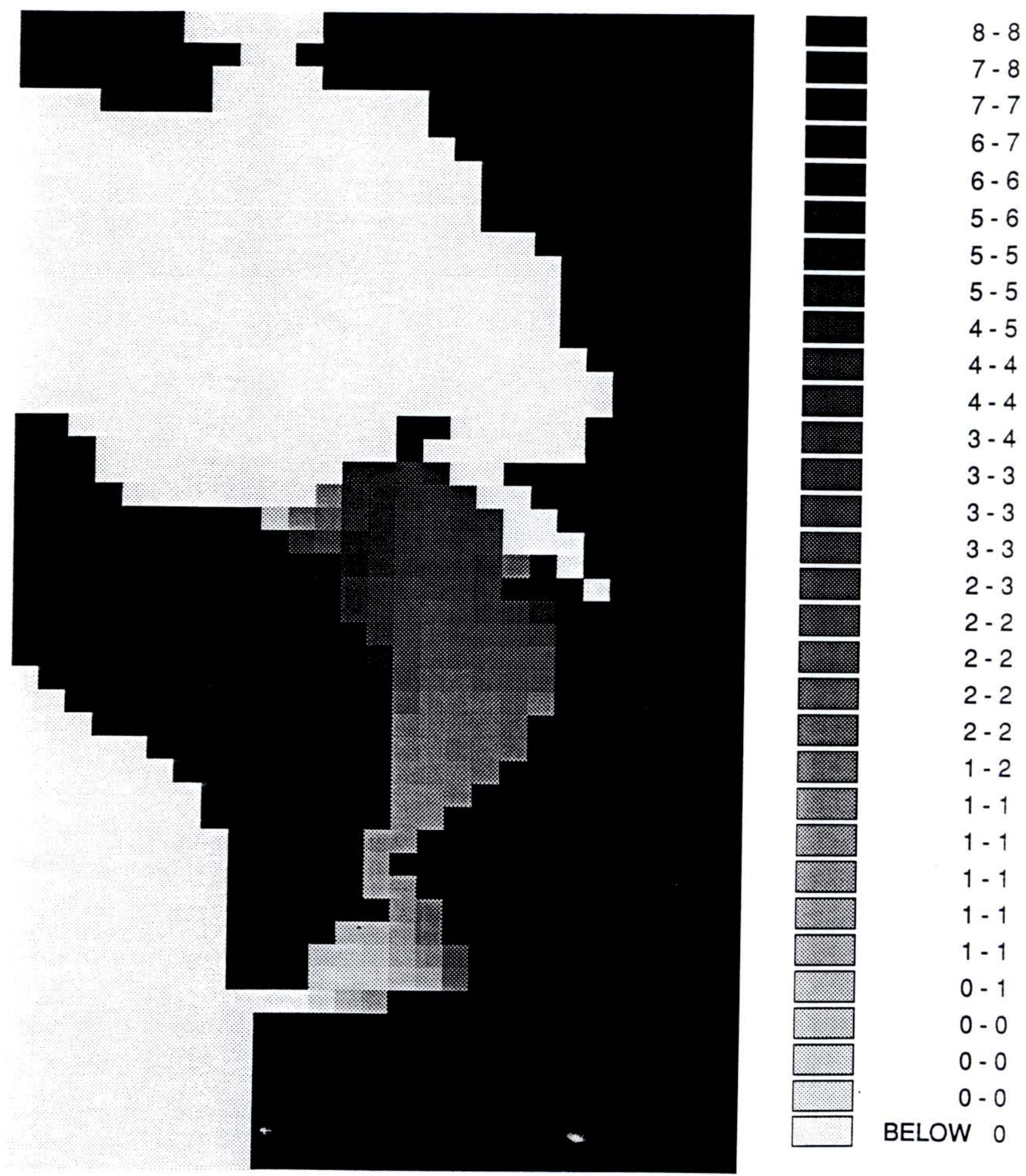

Figure 5. Computation of the residence time for each cell of the area included in the biological model. The longest residence time are shown along the inner Oléron coast and stage from 10 days at that place, to 0 days at the Maumusson Pertuis in the south part of the Bay, where the water is evacuated. 


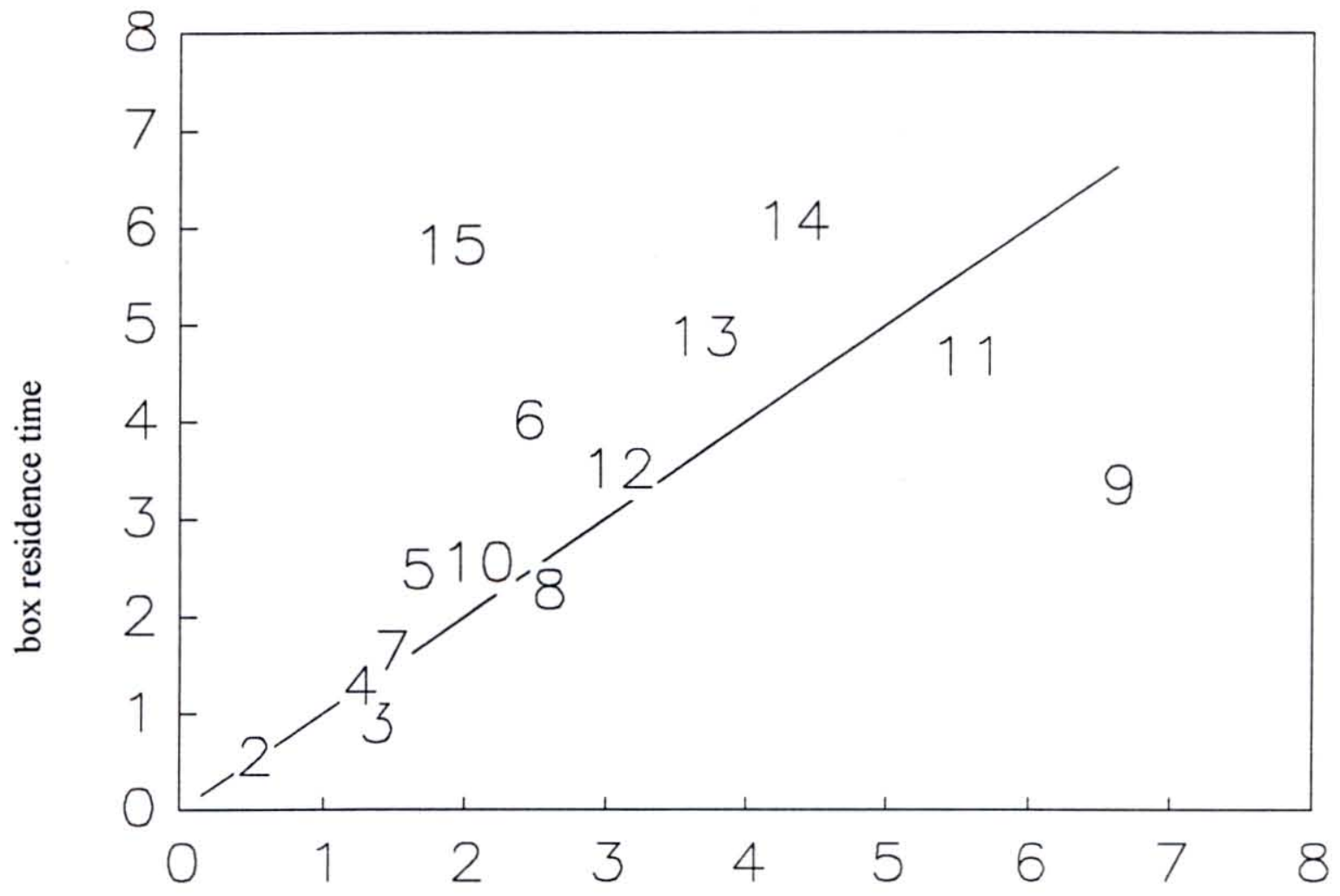

celll averaged residence time

Figure 6. Comparison of the residence time (days) derived from the matricial computation directly applied to the $15 \times 15$ transition matrix of the box design (y axis) and the average of the residence time of the cells contained within each box. The distance to the diagonal represents the modification provided by the box design to the residence time considered as a characteristic of the bay. 
instantaneous velocity fields used for the residual flows computation in this study, showed many discrepancies with the residual and linear solution (Raillard, unpub., fig. 7). To make the transport more realistic, an idea could be to work with lagrangian instead of eulerian residual terms. For instance, the computation of trajectories (fig. 8) could be used to estimate a new transition matrix. In this example, trajectories were computed for each cell with the same departure time and a duration of 12 hrs. The figure shows that exchanges occurred between cells that were not spatially connected. To be complete, this computation should be achieved with departure hours randomly or systematically chosen, therefore resulting in an effective numerical dispersion correction for the residual eulerian formalism. From that new basic residual flows, the same matricial calculation would be performed to yield new estimations of the local and global residence time. 


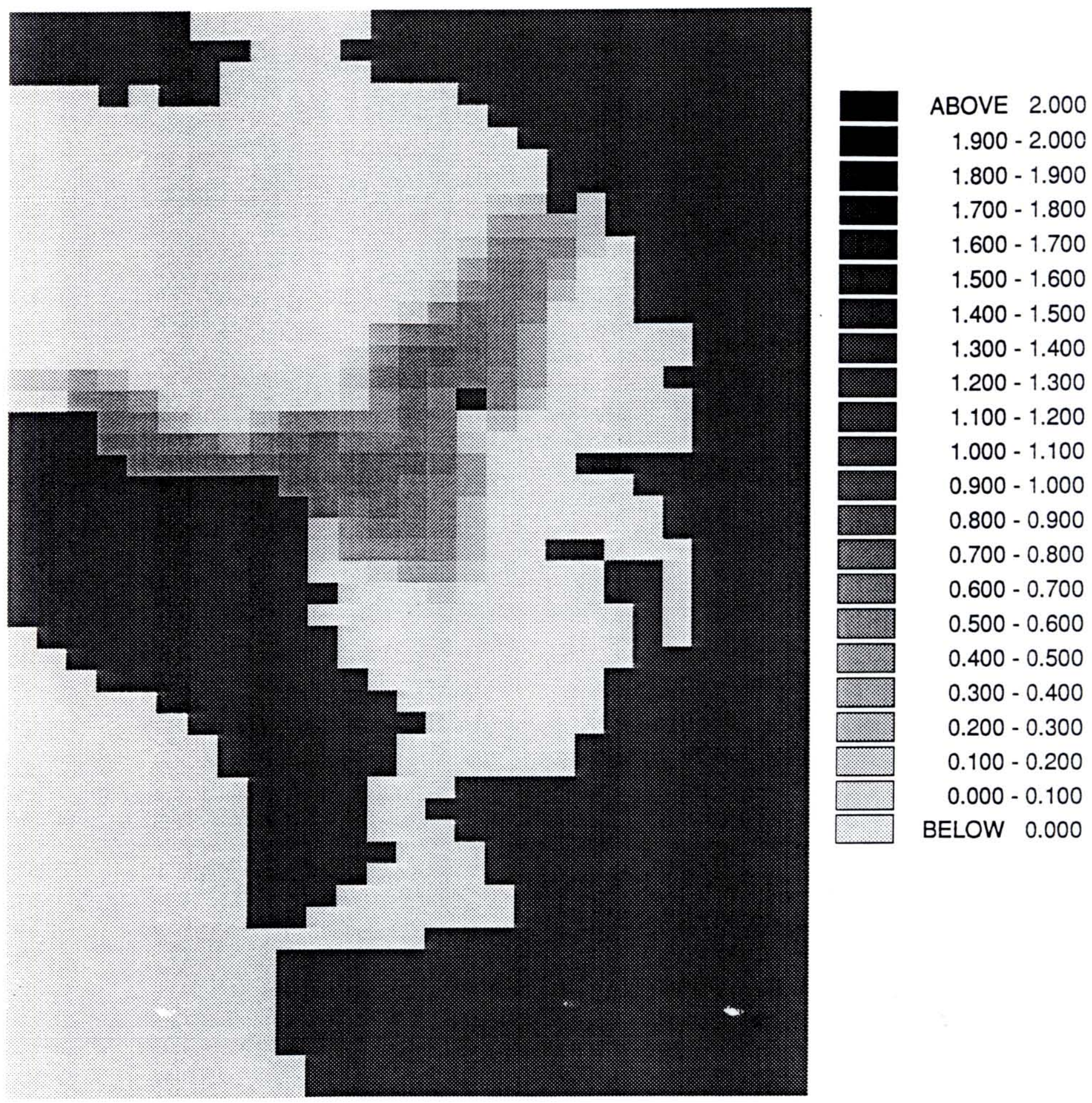

Figure 7. The matricial computation of the flows was used to simulate the advection of the water under the assumption of first order equation (7a). Compared to a pure advective transport simulated with instantaneous field velocities during 7 days ( $7 \mathrm{~b}$, Raillard, unpub.), the first model shows a lack of transversal dispersion due to the use of residual flows. 


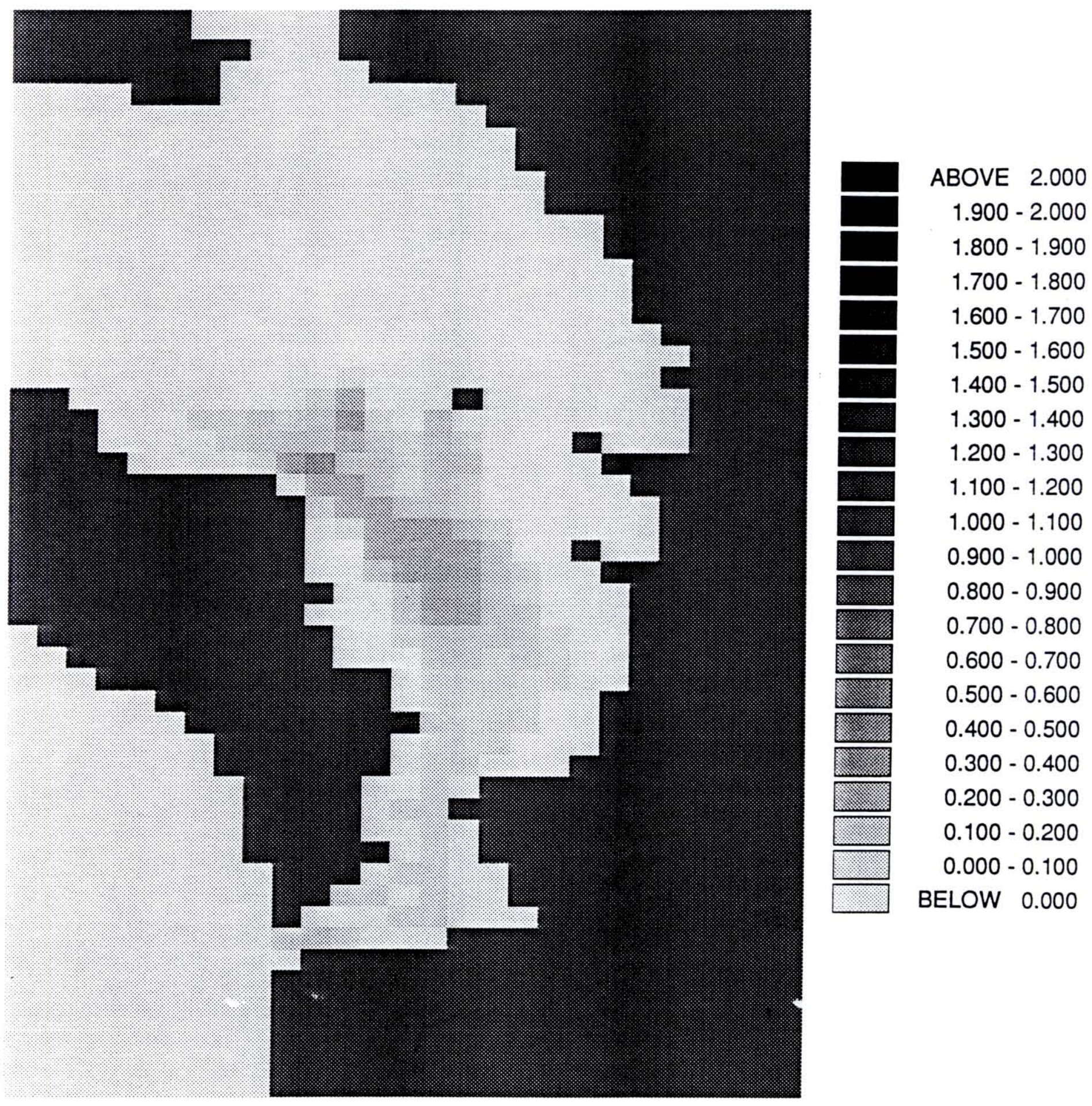

Figure 7. The matricial computation of the flows was used to simulate the advection of the water under the assumption of first order equation ( $7 a$ ). Compared to a pure advective transport simulated with instantaneous field velocities during 7 days ( $7 \mathrm{~b}$, Raillard, unpub.), the first model shows a lack of transversal dispersion due to the use of residual flows. 


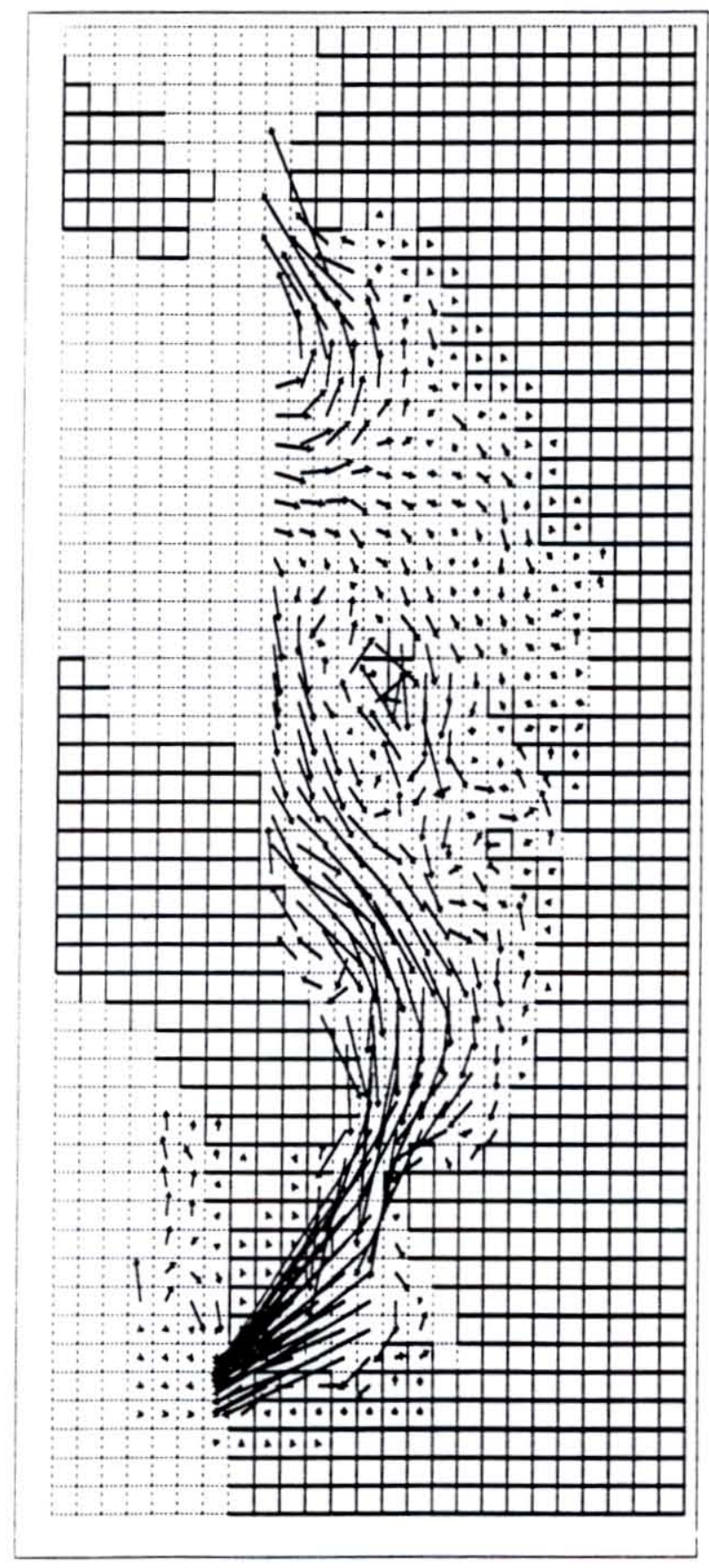

Figure 8. The systematic computation of trajectories for all the cells could be a way to correct the transition matrix of exchange probabilities between the cells. It would result in using lagrangian instead of eulerian residual flows. 